Sharif University of Technology
Scientia Iranica
Transactions E: Industrial Engineering
hCIENTIA

\title{
Two-stage game-theoretic approach to supplier evaluation, selection, and order assignment
}

\author{
J.C.P. Yu ${ }^{\mathrm{a}}$, H.M. Wee ${ }^{\mathrm{b}, *}$, S. Jeng ${ }^{\mathrm{b}}$, and Y. Daryanto ${ }^{\mathrm{b}, \mathrm{c}}$ \\ a. Department of Distribution Management, Takming University of Science and Technology, Taipei 114, Taiwan, ROC. \\ b. Department of Industrial and System Engineering, Chung Yuan Christian University, Chungli 32023, Taiwan, ROC. \\ c. Department of Industrial Engineering, Universitas Atma Jaya Yogyakarta, Yogyakarta 55281, Indonesia.
}

Received 26 November 2018; received in revised form 3 December 2019; accepted 8 February 2020

\section{KEYWORDS}

Supplier selection; Nash equilibrium; Supplier evaluation value;

Shapley value.

\begin{abstract}
This study proposes a framework for supplier evaluation, selection, and assignment that incorporates a two-stage game-theoretic approach method. The objective is to provide manufacturers with insights to choose suitable suppliers for different manufacturing processes. The framework applies to the decision logic of multiple manufacturing processes. In the first stage, a non-cooperative game model is utilized for supplier evaluation and selection. The interactive behaviors between a manufacturer and some supplier candidates are modeled and analyzed so that the Supplier Evaluation Value (SEV) can be obtained using the Nash equilibrium. In the second stage, the SEVs become the input for the Shepley values calculation of each supplier under a cooperative game model. The Shapley values are utilized to create a set of limited supplier allocation. This paper provides managerial insights to verify the viability of the proposed approach for supplier selection and allocation. Thus, it enables Supply Chain Management (SCM) manager to optimize supplier evaluation, selection, and order assignment.
\end{abstract}

(C) 2021 Sharif University of Technology. All rights reserved.

\section{Introduction}

Due to globalization, Supply Chain Management (SCM) managers in organizations must seek to reduce costs and increase their competitive advantage through global sourcing. The uncertain supply and demand makes global sourcing more challenging [1]. Supplier selection is a vital aspect of supply chain sourcing, particularly in a competitive environment. However, most enterprises have different criteria for selecting

\footnotetext{
*. Corresponding author. Tel.: +886-3-2654409;

Fax: +886-3-2654499

E-mail addresses: jonasyu@takming.edu.tw (J.C.P. Yu); weehm@cycu.edu.tw (H.M.Wee);

schnell.jeng@chrobinson.com (S.Jeng);

yosef.daryanto@uajy.ac.id (Y. Daryanto)
}

their suppliers [2]. Since each manufacturer faces multiple suppliers that possess different capabilities, SCM managers need to develop an effective mechanism to perform supplier evaluation, selection, and order allocation among the qualified suppliers. Different approaches such as multiple-criteria decision analysis, metaheuristic optimization, and game theory have been studied to optimize those decisions [3].

Game theory has been used in many business decisions including SCM . This paper explores how a manufacturer evaluates and selects qualified suppliers using game theory. This study proposes a two-stage model that connects the non-cooperative game model during supplier selection with the cooperative game model. The chosen suppliers are in a "cooperative game" relationship with the manufacturer to accomplish the expected supply quality.

The remainder of this paper is arranged as follows: 
Section 2 discusses previous research related to supplier selection, allocation problem, and game theory. Section 3 presents the proposed two-stage game theory model. Then, an experimental simulation is performed in Section 4 to study the proposed framework. Finally, Section 5 concludes the findings and suggests for future research .

\section{Literature review}

This section discusses previous research related to supplier selection and allocation problem as well as game theory in inventory and SCM.

\subsection{Supplier selection and allocation problem}

The supplier selection problem has attracted much attention over the years. Dickson [4] applied questionnaires to identify 23 influencing factors of supplier selection criteria and showed that product quality, delivery, and past performance were critical factors. Choi and Hartley [2] generalized 26 supplier evaluation criteria according to the research of Dickson [4] and Weber et al. [5]. Weber et al. [6] demonstrated that supplier facilities, capacity, and technological capabilities were related to supplier evaluation. Maurizio and Alberto [7] adopted financial ability, cost, technical competence, organizational culture, after-sales technical support, flexibility, quality management, and justin-time procurement as criteria for evaluating suppliers. Chan and Kumar [8] indicated that product cost was the primary consideration in selecting suppliers.

In recent years, new approaches have been developed for supplier selection and allocation problems. Freeman and Chen [9] used an Analytic Hierarchy Process (AHP)-Entropy-Technique for Order of Preference by Similarity to Ideal Solution (TOPSIS) framework for supplier selection by combining the traditional and environmental selection criteria. The aim is to integrate an environmentally friendly supplier into the supply chain. Neyestani et al. [10] studied supplier order allocation considering uncertain information on buyer demand and supplier delivery rate. Particle swarm optimization and genetic algorithm are used to solve the multi-objective model. Hosseini and Barker [11] combined the primary evaluating criteria (e.g., cost, quality, and delivery time) with some green and resilience criteria in supplier evaluation and selection. They proposed a Bayesian network to model the causal relationship among the variables. Tezenji et al. [12] developed an integrated supplier locationselection and order allocation model to minimize the establishment, transportation, and inventory-related costs. A systematic literature review on supplier selection research streams and future scope was presented by Wetzstein et al. [13]. Recently, Zaheri et al. [14] considered an all-unit quantity discount policy in the supplier selection problem. Adeinat and Ventura [15] developed an integrated pricing and supplier selection model when the demand was price sensitive. Suppliers' limited capacity and quality were taken into consideration. Rabieh et al. [16] integrated robust optimization and fuzzy programming for supplier selection under multiple uncertainties. A real case from automobile industry was provided.

Recently, some researchers started using game theory approach in supplier selection problem. Mohammaditabar et al. [17] studied supplier selection considering supply chain inventory costs under cooperative and non-cooperative relationships. Liu et al. [18] considered game theory for supplier selection, combined with the Analytic Network Process (ANP) method, entropy weight, and DEMATEL. Previous research has investigated the supplier selection process based on manufacturers' interests regardless of suppliers' concerns. The purpose of this study is to allow manufacturers to meet supplier evaluation criteria according to the concerns of manufacturers as well as suppliers.

\subsection{Game theory}

Game theory is derived from the "Theory of games and economic behavior" (von Neumann and Morgenstern [19]). The book was a significant achievement in Economics during the 20th century. Mathematical formulas represent interpersonal strategic thinking in a game. Through a series of deductions, game theory searches for maximum returns for participants. The well-known Nash equilibrium was an important milestone in game theory. Nash [20] proposed bargaining theory and noncooperative game theory to explain traditional game theory further. Most economists have adopted the Nash equilibrium. Essentially, game participants wish to produce the most favorable results for themselves. Under certain assumptions, the game theory uses a mathematical model to predict participants' behavior and help them choose optimal strategies involving conflicts of interest. General games are often expressed using standard formulas. In most studies, dynamic games have been expressed using a game tree [21]. Two types of game theory protocols are found in cooperative and non-cooperative games. The difference between these games lies in whether a binding force exists between participants: if so, the game is cooperative; if not, the game is non-cooperative. Shapley [22] investigated various pairing methods under the assumption that two parties cooperate. Based on game theory, Roth [23] conducted an empirical study with two types of protocol behaviors that described the crucial difference between cooperative and non-cooperative games.

Game theory works empirically in many circumstances and has become influential in a variety of disciplines beyond economics [24]. For example, Nash 
equilibrium becomes a powerful tool for understanding human interactions in many practical situations [25]. Game theory provides an analytical technique to study the interaction, including competition among some multiple agents of a system [26]. Game theory is a type of strategic thinking that provides a mathematical analysis method to configure a system and identify an optimal strategy for solving problems with conflicts of interest. It can be applied to fields such as politics, management, transportation, biology, and military strategy. Game theory can maximize the benefits of all players in a competitive environment and be used to analyze interactions between multiple decision-makers. Generally, a game involves a player who makes decisions, chooses a method during the game, selects a strategy for determining the action, and determines payoffs (i.e., outcome assessments). Finally, potential payoffs are quantified to determine whether a strategy is feasible accurately. At a specific time, participants have various information sources and variables. It is assumed here that each participant is rational and possesses a set of assessment criteria to select a solution and maximize benefits. When each participant considers their set of strategies to be optimal and they will settle for it, this set of strategies is called the equilibrium solution.

Game theory has been widely applied in recent years. Huang and $\mathrm{Li}$ [27] constructed a game model for advertising manufacturers (leaders) and retailers (followers) to explore the cooperative relationships between them. Leng and Parlar [28] applied game theory in supply chains and divided application areas into five categories. Under the assumption of fixed unit purchase cost, supply chain members competed and cooperated in inventory control. Numerous researchers have extended the application of game theory and used it to supply chain systems to establish cooperative relationships between suppliers and manufacturers. In civil engineering, Peldschus and Zavadskas [29] applied game theory and fuzzy theory for water supply decision-making with multiple criteria. In another study on cooperative games and supply chains, Hennet and Arda [30] proposed a decision-making assessment model that integrated queuing theory into game theory. This model was used to assess supply chain efficiency among conflicting partners. Besides, Bompard et al. [31] constructed a power market simulator by game theory. To test the simulator, the researchers compared real and simulated markets.

Long and $\mathrm{Yu}$ [32] used game theory to analyze the government and enterprises' optimal strategies for energy saving and carbon reduction. They found the Nash equilibrium solution and provided suggestions for sustainable energy policy. Chen et al. [33] utilized game theory to evaluate terrorist threats and appropriate responses. Runyan et al. [34] used multidimen- sional game theory to analyze difficulties in airplane design. Madani [35] conducted a literature review on how to solve conflicts in a non-cooperative water resource game. In electrical engineering, game theory has been applied in wireless networks [36]. Sharma and Gopal [37] introduced a new research direction, integrated reinforcement learning, and game theory and designed a reliable, intelligent controller. Dayi and Jianwei [38] proposed a simple optimal model to describe restrictions on carbon emissions and how regulations inhibited production. Based on game theory, they analyzed factors that influenced the government and enterprises. Also, numerous researchers have applied game theory to computer science. Liu et al. [39] proposed a multi-objective game theory using the Markov process and Shapley value to assess the satisfaction of participants.

\subsection{Game theory application in SCM}

Purchasing and inventory management are two important activities in SCM. Purchasing plays a vital role because a qualified material supply differentiates the manufacturer's final goods including the cost and quality, while inventory management determines the efficiency of the operations [40-45]. Recently, people also recognize the importance of such decisions in terms of sustainability [46-48].

Some researchers have demonstrated that cooperative game theory could be applied to centralized inventory management systems to reduce costs and enhance customer service [49]. Zhao et al. [50] used game theory to analyze how vendors reduced lifecycles and environmental risks of materials and chose a strategy for reducing carbon emissions to develop a green supply chain. Besides, Zhao et al. [50] speculated that manufacturers would be influenced by punishment and reward systems developed by the government. Zhao et al. [51] evaluated various strategies designed by the government and manufacturers using game theory. They promoted green products through various games to simulate different circumstances and suggested a strategic decision framework for government agencies and vendors. As local concerns have become global, a carbon reduction project can, therefore, be developed through global cooperation. Wu et al. [52] also applied games to reduce costs and carbon dioxide emissions. Sadigh et al. [53] used the Nash equilibrium for supply chain decisions of pricing and inventory management. The model studied a multi-echelon supply chain that consists of multiple suppliers, single manufacturer, and multiple retailers with equal power. Recently, Nazari et al. [54] implemented Nash and Stackelberg game theory to solve the pricing and inventory problem in a closedloop supply chain.

To mitigate supply risk, manufacturers tend to have several suppliers. This study aims to explore how 


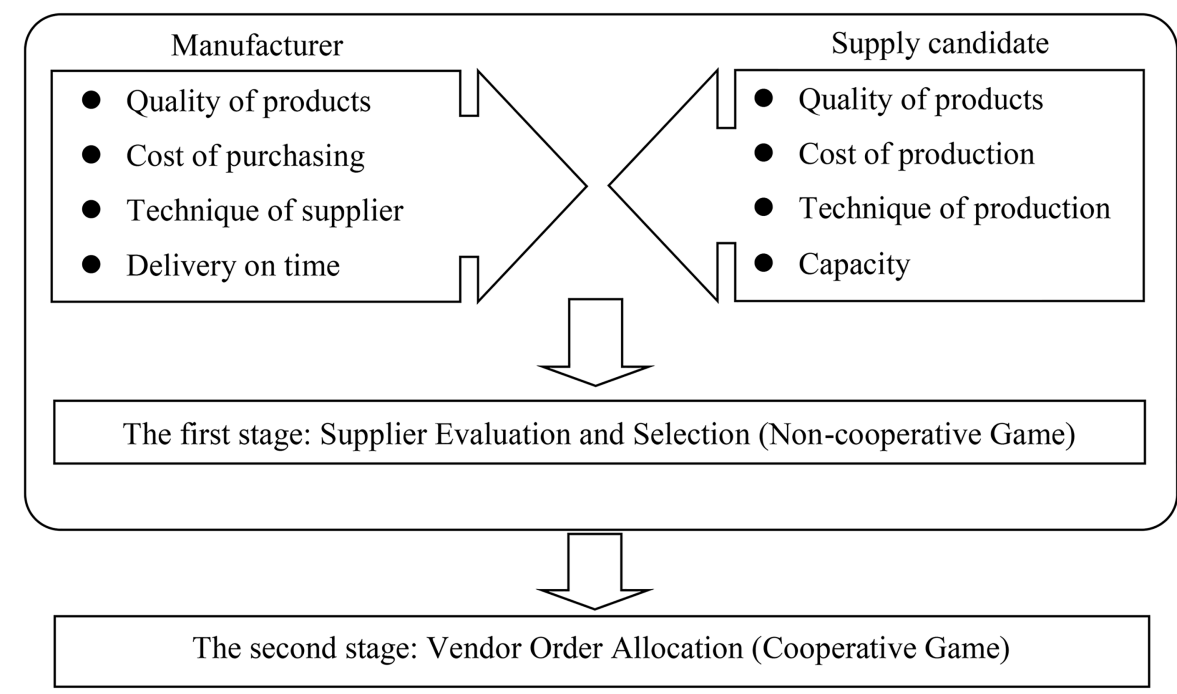

Figure 1. The proposed framework of the two-stage game-theoretic approach to supplier evaluation, selection, and order assignment.

manufacturers evaluate and select qualified suppliers by game theory. The evaluation rating develops a corresponding quantity of orders. In this situation, manufacturers and suppliers who strive for orders intend to achieve optimal expected benefit. They are in a "non-cooperative game" competitive relationship. Therefore, they must convince each other via competitiveness. In non-cooperative games, players do self-enforcing coordination. Each player optimizes the decision to minimize the cost of utilizing each resource and maximize the rewards it earns [55]. Nash equilibrium is widely used in non-cooperative games to help predict the outcome of the game that will make every player feel satisfied with what each other deserves. However, once they become qualified suppliers, they are in a "cooperative game" relationship to accomplish the expected supply quality. In a cooperative game, the Shapley value is applied to order allocation to suppliers in the network. Thus, this study proposes a two-stage model that connects the non-cooperative game model to the cooperative game model. The twostage model will analyze all the players' best responses and obtain their decisions. An experimental simulation is presented to study the proposed framework. It is clarified that the Supplier Evaluation Value (SEV) for each supplier and the Shapley values help the decisionmakers select qualified suppliers and allocate orders to the suppliers. This framework can be used to enhance the decision-making ability of a plant manager to control his or her supply chain and efficiently allocate suppliers in it.

\section{Modeling}

This study proposes a two-stage game-theoretic model that connects the non-cooperative game model to the cooperative game model. The framework is shown in Figure 1. In the first stage, supplier evaluation and selection are performed. The interactions between a manufacturer and its supplier candidates are modeled in the form of a non-cooperative game. When a manufacturer wants to construct a supply chain to produce its product, the behavior interactions between the manufacturer and supplier candidates will create a competitive environment. Nash equilibrium is employed to provide a steady state of moves concerning computing the objective functions for players. Every player interacts with other players to make optimal decisions. A game reaches equilibrium in a gametheoretic sense when each player's strategy is strategically stable and self-enforcing. A strategic stable or self-enforcing policy implies that no player can benefit from deviating from the equilibrium strategy. A finite non-cooperative game must have a Nash equilibrium. The Nash equilibrium is used to derive the SEV. The payoff functions will depend on the competence measurement in the manufacturing flow.

In the second stage, the interaction of all suppliers is modeled as a cooperative game. Shapley values measure the marginal contribution of each supplier in all manufacturing processes. The objective is to assign a limited vendor order to qualified suppliers efficiently. Multiple suppliers are organized into coalition groups about figuring the threshold majority to arrange appropriate and optimal supplier distribution in a manufacturing flow. Later, the Shapley value vector is used to allocate the order to all suppliers.

\subsection{Supplier evaluation game}

The two-player non-cooperative game for supplier evaluation is defined as follows:

(a) Player $i$ : The model has only two players. $i=$ 
Table 1. A $J$-by- $K$ payoff matrix for the supplier evaluation game $\left(\psi_{i}, i=1,2\right)$.

\begin{tabular}{cccccc}
\hline & \multicolumn{5}{c}{ Supplier } \\
\cline { 2 - 6 } Manufacturer & $\boldsymbol{S}_{\mathbf{1}}$ & $\boldsymbol{S}_{\mathbf{2}}$ & $\ldots$ & $\boldsymbol{S}_{K}$ & $\begin{array}{r}\text { The probability of } \\
\text { manufact urer mixed } \\
\text { strategy }\end{array}$ \\
\hline$M_{1}$ & $\psi_{i}\left(M_{1}, S_{1}\right)$ & $\psi_{i}\left(M_{1}, S_{2}\right)$ & $\ldots$ & $\psi_{i}\left(M_{1}, S_{K}\right)$ & $\omega_{1}\left(M_{1}\right)$ \\
$M_{2}$ & $\psi_{i}\left(M_{2}, S_{1}\right)$ & $\psi_{i}\left(M_{2}, S_{2}\right)$ & $\ldots$ & $\psi_{i}\left(M_{2}, S_{K}\right)$ & $\omega_{1}\left(M_{2}\right)$ \\
$\vdots$ & $\vdots$ & $\vdots$ & $\vdots$ & $\vdots$ & $\vdots$ \\
$\begin{array}{c}\text { The probability } \\
\text { of supplier }\end{array}$ & $\psi_{i}\left(M_{j}, S_{1}\right)$ & $\psi_{i}\left(M_{j}, S_{2}\right)$ & $\ldots$ & $\psi_{i}\left(M_{j}, S_{K}\right)$ & $\omega_{1}\left(M_{j}\right)$ \\
mixed strategy & $\omega_{2}\left(S_{1}\right)$ & $\omega_{2}\left(S_{2}\right)$ & $\ldots$ & $\omega_{2}\left(S_{K}\right)$ & \\
\hline
\end{tabular}

$\{1,2\}=\{$ Manufacturer, Supplier $\}$. The player not only plays a role as a person but also as a group, where the manufacturer is the supply chain driver that produces the final product;

(b) Strategy space $\Theta_{i}$ : A set of all possible strategies of two players in a game. When player $i$ has $n$ pure strategies, $\Theta_{i}=\left\{s_{i}^{1}, \ldots, s_{i}^{n}\right\}$;

(c) Payoff $\Psi_{i}$ : The utility or the expected utility of a player as a function of the strategy chosen by the manufacturer and suppliers.

Let $\Phi=\left\{i, \Theta_{i}, \Psi_{i}\right\}$ be such a normal form game. This game cannot determine the pure strategy of the Nash equilibrium because this game probably does not enjoy Nash equilibrium. However, every finite normal form game has a mixed strategy Nash equilibrium. Thus, this study derives another strategic game from $\Phi$, called the mixed extension of $\Phi$, in which the actions of each player $i$ are the set of all mixed strategies in $\Phi$. The concept is adopted from Cheheltani and Ebadzadeh [56] and Wu [57].

The Nash equilibrium mix strategy is identical to the stochastic state. It can predict the outcome of a game by capturing the stochastic regularity. In this case, manufacturers and supplier candidates possess all the past information about their payoff and other players' behavior. This situation helps each player predict the upcoming choices of other players to decide on a strategy.

Let $J$ and $K$ denote the number of pure strategies in $\Theta_{1}$ and $\Theta_{2}$ for the manufacture and supplier, respectively. They are written in $\Theta_{1}=\left\{M_{1}, M_{2}, \ldots, M_{J}\right\}$ and $\Theta_{2}=\left\{S_{1}, S_{2}, \ldots, S_{K}\right\}$. Suppose $\omega_{i}^{n}$ is the probability that player $i$ will play $s_{i}^{n}$ strategy. Therefore, the mixed strategy for player $i$ is $\left(\omega_{i}^{1}, \ldots, \omega_{i}^{n}\right)$. For $N=1, \ldots, n$, the condition for $\omega_{i}^{n}$ is $0 \leq \omega_{i}^{n} \leq 1$ and $\sum_{N=1}^{n} \omega_{i}^{N}=1$. This study uses $\omega_{i}$ to denote an arbitrarily mixed strategy from the set of probability distributions over
$\Theta_{i}$, just as this study uses $s_{i}$ to denote an arbitrary pure strategy from $\Theta_{i}$.

Table 1 shows the payoff matrix $(J \times K)$ for the supplier evaluation created based on the manufacturer and supplier strategies and interactions.

The manufacturer's expected payoff from playing the pure strategy $M_{j}$ when the manufacturer believes that the supplier will play the strategies $\Theta_{2}=\left\{S_{1}, S_{2}, \ldots, S_{K}\right\}$ with the probability $\omega_{2}=$ $\left\{\omega_{2}\left(S_{1}\right), \omega_{2}\left(S_{2}\right), \ldots, \omega_{2}\left(S_{K}\right)\right\}$ can be expressed as:

$$
\sum_{k=1}^{K} \omega_{2}\left(S_{k}\right) \cdot \psi_{1}\left(M_{j}, S_{k}\right) .
$$

We can also calculate the manufacturer's expected payoff from performing the other pure strategies $\Theta_{1}=$ $\left\{M_{1}, M_{2}, \ldots, M_{J}\right\}$. This calculation leads to the manufacturer's expected payoff from performing the mixed strategy $\omega_{1}=\left\{\omega_{1}\left(M_{1}\right), \omega_{1}\left(M_{2}\right), \ldots, \omega_{1}\left(M_{J}\right)\right\}$ as follows:

$$
\begin{aligned}
E_{1}\left(\omega_{1}, \omega_{2}\right) & =\sum_{j=1}^{J} \omega_{1}(M j)\left[\sum_{k=1}^{K} \omega_{2}\left(S_{k}\right) \cdot \psi_{1}\left(M j, S_{k}\right)\right] \\
& =\sum_{j=1}^{J} \sum_{k=1}^{K} \omega_{1}(M j) \cdot \omega_{2}\left(S_{k}\right) \cdot \psi_{1}\left(M j, S_{k}\right),
\end{aligned}
$$

where $\omega_{1}\left(M_{j}\right)$ and $\omega_{2}\left(S_{k}\right)$ are the probability that the manufacturer plays $M_{j}$ and supplier plays $S_{k}$, where $0 \leq \omega_{1}\left(M_{j}\right), \omega_{2}\left(S_{k}\right) \leq 1$ for $k=1, \ldots, K$ and $j=$ $1, \ldots, J$. Also, $\sum_{j=1}^{J} \omega_{1}\left(M_{j}\right)=1$ and $\sum_{k=1}^{K} \omega_{2}\left(S_{k}\right)=1$.

Eq. (2) is actually the weighted sum of the expected payoff for each of the pure strategies of the manufacturer $\Theta_{1}=\left\{M_{1}, M_{2}, \ldots, M_{J}\right\}$. Thus, for the mixed strategy $\omega_{1}\left(M_{1}\right), \omega_{1}\left(M_{2}\right), \ldots, \omega_{1}\left(M_{J}\right)$ to be the best response for the manufacturer to supplier's 
mixed strategy $\omega_{2}\left(S_{k}\right)$, the following should be held: $\omega_{1}\left(M_{j}\right)>0$ only if:

$$
\begin{aligned}
& \sum_{k=1}^{K} \omega_{2}\left(S_{k}\right) \cdot \psi_{1}\left(M_{j}, S_{k}\right) \geq \sum_{k=1}^{K} \omega_{2}\left(S_{k}\right) \cdot \psi_{1}\left(M_{\hat{j}}, S_{k}\right) \\
& \quad \forall M_{\hat{j}} \in \Theta_{1},
\end{aligned}
$$

for every $M_{j}$ in $S_{1}$. That is, for a mixed strategy to be the best response to $\omega_{2}$, a positive probability on a purely given strategy only should be placed if the pure strategy itself is the best response to $\omega_{2}$ [58]. Contrarily, if the manufacturer has several pure strategies that are the best responses to $\omega_{2}$, then any mixed strategy that puts all of its probability on some or all of these pure-strategy best responses (and zero probability on all other pure strategies) is also the best response for the supplier to $\omega_{2}$. This study computes supplier's expected payoff when the manufacturer and supplier perform the mixed strategies $\omega_{1}$ and $\omega_{2}$, respectively. If supplier predicts that the manufacturer applies the strategy set $\Theta_{1}$ with the probabilities $\left\{\omega_{1}\left(M_{1}\right), \omega_{1}\left(M_{2}\right), \ldots, \omega_{1}\left(M_{J}\right)\right\}$, then the supplier's expected payoff from performing the strategy set $\Theta_{2}$ with the probabilities $\left\{\omega_{2}\left(S_{1}\right), \omega_{2}\left(S_{2}\right), \ldots, \omega_{2}\left(S_{k}\right)\right\}$ is:

$$
\begin{aligned}
E_{2}\left(\omega_{1}, \omega_{2}\right) & =\sum_{k=1}^{K} \omega_{2}\left(S_{k}\right)\left[\sum_{j=1}^{J} \omega_{1}\left(M_{j}\right) \cdot \psi_{2}\left(M_{j}, S_{k}\right)\right] \\
& =\sum_{j=1}^{J} \sum_{k=1}^{K} \omega_{2}\left(S_{k}\right) \cdot \omega_{1}\left(M_{j}\right) \cdot \psi_{2}\left(M j, S_{k}\right) .
\end{aligned}
$$

$E_{1}\left(\omega_{1}, \omega_{2}\right)$ and $E_{2}\left(\omega_{1}, \omega_{2}\right)$ rehash Nash's equilibrium requirement that any player's mixed strategy should be the best reaction to the mixed strategy of other players. $\omega_{1}^{*}$ and $\omega_{2}^{*}$ represent the optimal mixed strategies for the manufacturer and supplier candidate, respectively. For a pair of mixed strategies $\left(\omega_{1}^{*}, \omega_{2}^{*}\right)$ to become Nash equilibrium, $\omega_{1}^{*}$ should meet:

$$
\begin{aligned}
& E_{1}\left(\omega_{1}{ }^{*}, \omega_{2}{ }^{*}\right) \geq E_{1}\left(\omega_{1}, \omega_{2}^{*}\right), \\
& E_{2}\left(\omega_{1}^{*}, \omega_{2}{ }^{*}\right) \geq E_{2}\left(\omega_{1}, \omega_{2}{ }^{*}\right),
\end{aligned}
$$

where every probability distribution $\omega_{1}$ is over $\Theta_{1}$, and for $\omega_{2}^{*}$ every probability distribution $\omega_{2}$ is over $\Theta_{2} . \omega_{1}^{*}$ and $\omega_{2}^{*}$ represent the optimal mixed strategies for manufacturer and supplier in the game, respectively.

The probability vector of the optimal strategy $\left(\omega_{1}^{*}, \omega_{2}^{*}\right)$ is $\omega_{1}^{*}=\left\{\omega_{1}^{*}\left(M_{1}\right), \omega_{1}^{*}\left(M_{2}\right), \ldots, \omega_{1}^{*}\left(M_{J}\right)\right\}$ with actions $\left\{M_{1}, M_{2}, \ldots, M_{J}\right\}$ for the manufacturer and the vector $\omega_{2}^{*}=\left\{\omega_{2}^{*}\left(S_{1}\right), \omega_{2}^{*}\left(S_{2}\right), \ldots, \omega_{2}^{*}\left(S_{K}\right)\right\}$ with actions $\left\{S_{1}, S_{2}, \ldots, S_{K}\right\}$ for the supplier candidate. Player 1 (i.e., the manufacturer) pays a minus cost $(-)$ because the manufacturer gains a profit from supplier's responses. Player 2 (i.e., the supplier) pays a plus cost
$(+)$, which means the supplier pays according to the manufacturer's evaluation. Let $v_{i}$ be the $i$ th evaluation absolute value for the supplier candidates and one has:

$$
\begin{aligned}
& v_{i, 2}\left(\omega_{1}^{*}, \omega_{2}{ }^{*}\right)=v_{i} \\
& =\left|\sum_{j=1}^{J} \sum_{k=1}^{K} \omega_{1}^{*}\left(M_{j}\right) \cdot \omega_{2}{ }^{*}\left(S_{k}\right) \cdot \psi_{2}\left(M_{j}, S_{k}\right)\right|, \\
& \omega_{1}^{*}\left(M_{j}\right), \omega_{2}^{*}\left(S_{k}\right) \in N . E .
\end{aligned}
$$

Therefore, $v_{i}$ represents the evaluation value of the supplier candidates and is derived from two optimal strategy probabilities. The evaluation value will be used in the second stage of the model to calculate the Shapley value of each supplier.

\subsection{Order allocation game}

In this second stage, the interactions of all suppliers in the manufacturing process are equated with a cooperative game. The objective is to decide on the priority of order assignment to the supply chain, particularly when available suppliers are limited in a manufacturing process. In a cooperative game, we can use the Shapley value to divide the total gains among the players equitably. Shapley value uniquely determines the outcomes of the game.

The Shapley value considers multiple decisionmakers who generate marginal contributions in a cooperative game. We can compute the average contribution of each player with this formula. Before the formula calculates the Shapley value, it is assumed that all players' optimal results are utilized in the computation. Each player adds to a situation or coalition, which can generate the average contribution in a coalition. In various coalitions, when one player participates in a coalition, the formula can compute its marginal contributions within a cooperative game. The proposed model utilizes a majority coalition concept to analyze supplier allocation. The concept is based on party voting game. Here, the voters build a majority coalition to win. Each voter has a power that depends on how important they are to form a winning coalition. When the sum of SEVs of some suppliers reach the majority level threshold, the power index (i.e., Shapley value) of each supplier can be computed as we can construct the winning coalition.

All selected suppliers play an $N$-person game with $P=\{1,2, \ldots, N\}$. Each subset $V \subset P$ and where $v_{j} \neq 0, \forall \lambda \in V$ is called a coalition. The function $f: V->R^{+}$is gained by assigning a positive real number to each element of $V$ (i.e., SEV) and $f(0)=0$, $V=\left\{v_{1}, v_{2}, . ., v_{i}, \ldots, v_{n}\right\}, i \in N$. Let $f(Z)=\sum_{i \in Z} v_{i}$, $v_{i} \in V, Z \subset \mathrm{P}$ be the value of coalition $Z$ with a cardinality of $z$. The vendor rating level, $L=$ $\left\{L_{1}, L_{2}, \ldots, L_{\lambda}, \ldots, L_{n}\right\}$, is derived from a majority of all SEVs of a manufacturing process. The corresponding 
threshold value is $H=\left\{h_{1}, h_{2}, \ldots, h_{\lambda}, \ldots, h_{n}\right\}$, where $0<h_{1}<h_{2}<\ldots<h_{n}$. Then:

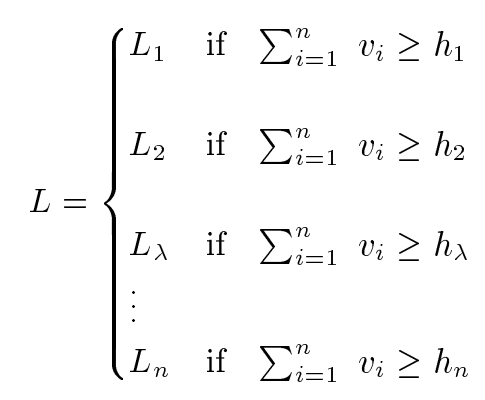

Different levels of evaluation are then set for supplier grouping based on the average value of the threshold interval. Each threshold is assumed as $h_{\lambda}=\left(v_{\max }-v_{\min }\right) / 2$ using the Alpcan method [59]. According to the output vector of all SEVs of the manufacturing process, the majority of competence levels are $L_{\lambda}$ if $\sum S E V s \geq h_{\lambda}$. Thus, all SEVs of suppliers formed a group of majority levels $L_{\lambda}$.

We can define the Shapley value of the $i$ th supplier as follows:

$$
\begin{aligned}
S V(i) & =\sum_{\substack{Z \subset X \\
i \in Z}} \frac{(z-1) !(n-z) !}{n !} \cdot(f(Z)-f(Z-\{i\})) \\
& =\sum_{\substack{Z_{w} \subset X \\
i \in Z_{w}}} \frac{(z-1) !(n-z) !}{n !} .
\end{aligned}
$$

The term $f(Z)-f(Z-\{i\})$ will always have a value of 0 or 1 . When $Z_{w}$ is a winning coalition, the value is 1 . In the opposite condition, the terms $Z-\{i\}$ and $f(Z)$ are 0 . The Shapley value $(S V(i))$ requires a winning coalition with $\sum_{i \in Z} v_{i} \geq L_{\lambda}$. The Shapley value of the $i$ th supplier expresses the relative competence value of different thresholds. In our model, the competence level of all suppliers is represented by these Shapley values. We can compute the order allocation for each qualified supplier in each process based on the supplier's Shapley values. The order allocation assigned to the $i$ th supplier is defined by:

$$
O(i)=S V(i) \times R_{j}, \quad i, j \in N,
$$

where $R_{j}$ is the total orders of the manufacturer in the $j$ th manufacturing process. The order allocation of the $i$ th supplier is derived by multiplying $S V(i)$ and $R_{j}$. Finally, the manufacturer can allocate orders to all qualified suppliers in each process.

\subsection{Solution procedure}

This procedure aims to find an acceptable allocation of order to qualified suppliers based on the expected marginal contribution by creating a minimum set of order deployment costs. The solution procedure is as follows:
1. Assume a set of suppliers for $k=1$ to $K$;

2. Considering a non-cooperative game performs the supplier evaluation, compute the manufacturer and supplier mixed strategy Nash equilibrium and find the SEV value;

3. Set the evaluation levels and find the threshold value $h_{\lambda}$ at the evaluation level $L_{\lambda}$;

4. Considering that a cooperative game performs the supply chain allocation, compute the Shapley value of the supplier based on the threshold value $h_{\lambda}$;

5. If coalition $\sum_{\mathrm{i} \in \mathrm{Z}} v_{i} \geq h_{\lambda}$, then find an adjustable scale (Step 6); otherwise, go to step 4;

6. Find an adjustable scale and adjust the preference of scale by increasing or decreasing the value within the total Shapley value. Allocate the available orders to the suppliers.

\section{The application of the two-stage game-theoretic approach}

The framework is mainly applied when manufacturers construct the decision logic of multiple manufacturing processes and supplier candidates. The framework uses a two-stage game-theoretic approach to select qualified suppliers and classify them according to competence indicators. Based on ratings, manufacturers propose the corresponding quantity of orders. In the supplier evaluation game, the manufacturer is player 1 and the decision-maker who chooses qualified suppliers for the manufacturing process. Suppose that $M$ denotes the strategy space of the manufacturer: $M=\left\{M_{1}, M_{2}, M_{3}, M_{4}\right\}=\{$ quality of products, cost of manufacture, delivery performance, and technique of supplier $\}$ adopted from Chan and Kumar [8]. The supplier is player 2. Both players predict the behavior/strategy of their opponents and decide on their response. Table 2 shows the $4 \times 4$ payoff matrix from the manufacturer and supplier interactions.

The variable $F_{j, k}$ denotes the manufacturer's request from each supplier at each strategy, where the value is assumed to be classified from 1 to 10 , as shown in Table $3 . W_{j}$ denotes the strategy-weighted value, where it is assumed to be classified from 1 to 4 , indicating the significances of the specific strategies.

$S$ denotes the strategy space of the supplier: $S_{k}=\left\{S_{1}, S_{2}, S_{3}, S_{4}\right\}=$ quality of products, cost of manufacture, delivery performance, and technique of supplier\}, adopted from Chan and Kumar [8]. $C_{k}$ denotes the set of the supplier's reputation: $C_{k}=$ $\left\{C_{1}, C_{2}, C_{3}, C_{4}\right\}$, where the reputation value or score is assumed to be classified from 1 to 10 . Table 4 shows the score for the strategy space of the supplier.

The formulas for the suppliers' strategies are as follows: 
Table 2. A payoff matrix for the supplier evaluation game.

\begin{tabular}{ccccc}
\hline \multirow{2}{*}{$\boldsymbol{M}_{\boldsymbol{j}}$} & \multicolumn{4}{c}{$\boldsymbol{S}_{\boldsymbol{k}}$} \\
\cline { 2 - 5 } & $\begin{array}{c}\text { Quality of } \\
\text { products }\end{array}$ & $\begin{array}{c}\text { Cost of } \\
\text { manufacture }\end{array}$ & $\begin{array}{c}\text { Delivery } \\
\text { performance }\end{array}$ & $\begin{array}{c}\text { Technique of } \\
\text { supplier }\end{array}$ \\
\hline Quality of products & $\left(S_{1}-F_{1,1}\right) W_{1} C_{1}$ & $\left(S_{2}-F_{1,1}\right) W_{2} C_{2}$ & $\left(S_{3}-F_{1,1}\right) W_{3} C_{3}$ & $\left(S_{4}-F_{1,1}\right) W_{4} C_{4}$ \\
Cost of manufacture & $\left(S_{1}-F_{2,1}\right) W_{1} C_{1}$ & $\left(S_{2}-F_{2,1}\right) W_{2} C_{2}$ & $\left(S_{3}-F_{2,1}\right) W_{3} C_{3}$ & $\left(S_{4}-F_{2,1}\right) W_{4} C_{4}$ \\
Delivery performance & $\left(S_{1}-F_{3,1}\right) W_{1} C_{1}$ & $\left(S_{2}-F_{3,1}\right) W_{2} C_{2}$ & $\left(S_{3}-F_{3,1}\right) W_{3} C_{3}$ & $\left(S_{4}-F_{3,1}\right) W_{4} C_{4}$ \\
Technique of supplier & $\left(S_{1}-F_{4,1}\right) W_{1} C_{1}$ & $\left(S_{2}-F_{4,1}\right) W_{2} C_{2}$ & $\left(S_{3}-F_{4,1}\right) W_{3} C_{3}$ & $\left(S_{4}-F_{4,1}\right) W_{4} C_{4}$ \\
\hline
\end{tabular}

Table 3. The manufacturer's request $\left(F_{j, k}\right)$.

\begin{tabular}{cccccc}
\hline & \multicolumn{5}{c}{ Player 2} \\
\cline { 2 - 5 } Player $\mathbf{1}$ & $\boldsymbol{S}_{\boldsymbol{1}}$ & $\boldsymbol{S}_{\boldsymbol{2}}$ & $\boldsymbol{S}_{\mathbf{3}}$ & $\boldsymbol{S}_{\boldsymbol{4}}$ & $\boldsymbol{W}_{\boldsymbol{j}}$ \\
\hline$M_{1}$ & 5.5 & 4.5 & 3.5 & 4.5 & 2.5 \\
$M_{2}$ & 4.5 & 5.5 & 3.5 & 4.5 & 2.0 \\
$M_{3}$ & 4.5 & 4.5 & 5.5 & 3.5 & 1.0 \\
$M_{4}$ & 4.5 & 4.5 & 3.5 & 5.5 & 1.5 \\
\hline
\end{tabular}

Table 4. The reputation value for the strategy space of Player 2.

\begin{tabular}{|c|c|c|c|c|}
\hline Score & $S_{1}$ & $S_{2}$ & $S_{3}$ & $S_{4}$ \\
\hline 10 & $100 \%$ & & $100 \%$ & $2 \leqq C_{p k}$ \\
\hline 9 & $98 \%$ & & $98 \%$ & $1.83 \leqq C_{p k}<2$ \\
\hline 8 & $96 \%$ & & $96 \%$ & $1.67 \leqq C_{p k}<1.83$ \\
\hline 7 & $94 \%$ & & $94 \%$ & $1.5 \leqq C_{p k}<1.67$ \\
\hline 6 & $92 \%$ & {$\left[\frac{P_{M}}{P_{S}} \times 10\right]$} & $92 \%$ & $1.33 \leqq C_{p k}<1.5$ \\
\hline 5 & $90 \%$ & & $90 \%$ & $1.17 \leqq C_{p k}<1.33$ \\
\hline 4 & $88 \%$ & & $88 \%$ & $1 \leqq C_{p k}<1.17$ \\
\hline 3 & $86 \%$ & & $86 \%$ & $0.83 \leqq C_{p k}<1$ \\
\hline 2 & $84 \%$ & & $84 \%$ & $0.67 \leqq C_{p k}<0.83$ \\
\hline 1 & $82 \%$ & & $82 \%$ & $C_{p k}<0.67$ \\
\hline
\end{tabular}

- Quality of product evaluation: This study defines $S_{1}$ as the quality capability of the $i$ th supplier, which is the product yield rate. The formula is expressed as:

\section{$\frac{\text { Good units }}{\text { Production units }} \%$.}

- Cost of manufacturer evaluation: This study defines $S_{2}$ as the cost capability of the $i$ th supplier. The formula is expressed as follows:

$$
\frac{\text { Bargain price of manufacturer }\left(P_{M}\right)}{\text { Bargain price of supplier }\left(P_{S}\right)} \times 10 \text {. }
$$

- Delivery performance evaluation: This study defines $S_{3}$ as the delivery capability of the $i$ th supplier, given below:

$$
\frac{\text { Number of on - time deliveries }}{\text { Total number of deliveries }} \% \text {, }
$$

where $C_{\max , i}$ and $C_{\min , i}$ are the greatest and smallest delivery performances, respectively.

- The technique of supplier evaluation: This study defines $S_{4}$ as the process capability of the $i$ th supplier, given below:

$$
C_{p k}=\min \left\{\frac{U S L-u}{3 \sigma}, \frac{u-L S L}{3 \sigma}\right\} .
$$

In this interaction, the manufacturer's payoff for selecting a specific strategy when the supplier has taken a choice results in the manufacturer's gain and a loss to the supplier. The sum of losses for the supplier is illustrated, and it is assumed that the manufacturer tries to maximize her gain. The minus cost (-) indicates the manufacturer gaining a payoff from the supplier's response. The plus cost $(+)$ means that the supplier pays as a result of the manufacturer's response. From Eq. (2), the payoff formula for the $k$ th strategy of the supplier and the $j$ th strategy of the manufacturer is given by:

$$
E_{1}=\sum_{j=1}^{4} \sum_{k=1}^{4} \omega_{1}^{*}\left(M_{j}\right) \cdot \omega_{2}^{*}\left(S_{k}\right) \cdot\left(S_{k}-F_{j, k}\right) W_{k} C .
$$

In this non-cooperative interaction, we assume a zerosum game. Hence, from Eq. (4), the payoff formula of the manufacturer can be formulated as follows:

$$
E_{2}=-\sum_{j=1}^{4} \sum_{k=1}^{4} \omega_{1}^{*}\left(M_{j}\right) \cdot \omega_{1}^{*}\left(S_{k}\right) \cdot\left(S_{k}-F_{j, k}\right) W_{k} C .
$$

Strategy space $\Theta_{i}$ is a set of all possible strategies of two players in a game. Each of the pure strategies $\Theta_{1}=$ $\left\{M_{1}, M_{2}, M_{J}\right\}$ is given in Eq. (1), where the weights are the probabilities $\omega_{1}=\left\{\omega_{1}\left(M_{1}\right), \omega_{1}\left(M_{2}\right), \ldots, \omega_{1}\left(M_{J}\right)\right\}$ and the strategy sets $\Theta_{1}$ and $\Theta_{2}$ represent a uniform distribution.

The above numerical example simulates the proposed two-stage game theory framework. First, the model studies the behavioural interactions between the manufacturer and supply candidates. The model created Nash equilibrium points to compute the SEV. 
Table 5 shows the numerical example for calculating the SEVs. Given the vector output for all the values, this study uses Eq. (8) to compute the majority of threshold values (i.e., $\left.m_{h}\right)$. Then, all the SEVs are utilized to calculate the supplier's Shapley value based on Alpcan and Başar's [59] formula. Table 6 presents the Shapley values and allocation. The result shows how Shapley values of each supplier determine different cases of order allocation. Based on the example, we illustrate the ability of the proposed game theory framework and solution procedure to evaluate and select suppliers, as well as allocate the required supplies.

\section{Conclusions and future works}

This paper presented a two-stage game theory framework for supplier evaluation, selection, and allocation in a competing supply chain. The framework applied to the decision logic of multiple manufacturing processes. In the first stage, a non-cooperative game model was utilized to analyze the interactive behavior between a manufacturer and some suppliers. All the parties possess the past information about their payoffs and the other players' behaviors. The model used a mixed strategy Nash equilibrium to obtain the Supplier Evaluation Value (SEV). In the second stage,

Table 5. Numerical examples for generation of Supplier Evaluation Values (SEVs).

\begin{tabular}{|c|c|c|c|c|c|c|c|c|}
\hline Process & Supplier & $S_{1}$ & $S_{2}$ & $S_{3}$ & $S_{4}$ & $\begin{array}{c}\text { Player \#1 } \\
\text { strategy }\end{array}$ & $\begin{array}{c}\text { Player\# } 2 \\
\text { strategy }\end{array}$ & SEV \\
\hline \multirow{4}{*}{ I } & A & 9 & 8 & 7 & 10 & 1 & 3 & 30.3 \\
\hline & B & 8 & 9 & 6 & 8 & 1 & 3 & 20.0 \\
\hline & $\mathrm{C}$ & 6 & 6 & 7 & 9 & 1,4 & 3 & 23.8 \\
\hline & $\mathrm{D}$ & 7 & 7 & 6 & 7 & $1,2,4$ & 3 & 17.1 \\
\hline \multirow{4}{*}{ II } & $\mathrm{E}$ & 8 & 6 & 7 & 7 & 1 & 2 & 21.2 \\
\hline & $\mathrm{F}$ & 6 & 8 & 9 & 8 & 2 & 1 & 27.9 \\
\hline & G & 7 & 6 & 8 & 9 & 1 & 2 & 21.9 \\
\hline & $\mathrm{H}$ & 6 & 8 & 9 & 7 & 2 & 1 & 27.1 \\
\hline \multirow{4}{*}{ III } & I & 8 & 6 & 9 & 10 & 1 & 2 & 24.0 \\
\hline & $\mathrm{J}$ & 6 & 7 & 10 & 6 & 3 & 4 & 34.0 \\
\hline & $\mathrm{K}$ & 9 & 7 & 7 & 7 & 1 & 3 & 27.0 \\
\hline & $\mathrm{L}$ & 7 & 8 & 7 & 8 & 1 & 3 & 26.0 \\
\hline
\end{tabular}

Table 6. Results of computing the Shapley values and the allocation of suppliers.

\begin{tabular}{ccccc}
\hline $\begin{array}{c}\text { Manufacturing } \\
\text { processes }\end{array}$ & Suppliers & $\begin{array}{c}\text { Threshold value } \\
\boldsymbol{h}\end{array}$ & $\begin{array}{c}\text { Shapley values } \\
\boldsymbol{S} \boldsymbol{V}(\boldsymbol{i})\end{array}$ & $\begin{array}{c}\text { The allocation of } \\
\text { suppliers } \boldsymbol{O}(\boldsymbol{i})\end{array}$ \\
\hline \multirow{3}{*}{ I } & A & & 0.417 & 1250 \\
& B & 23.7 & 0.083 & 250 \\
& C & & 0.417 & 1250 \\
D & & 0.083 & 250 \\
& & & & 167 \\
II & E & & 0.083 & 833 \\
& F & & 0.417 & 167 \\
& G & & 0.083 & 833 \\
& H & & 0.417 & 833 \\
& I & & & 2500 \\
& J & & 0.167 & 833 \\
& K & & 0.500 & 833 \\
\hline
\end{tabular}


the interactions of all suppliers in the manufacturing process were equated with a cooperative game. When the sum of SEVs of some suppliers reach the majority level threshold, the power index (i.e., Shapley value) of each supplier can be computed by finding the winning coalition. The Shapley values became the basis for creating an evaluation mechanism for allocating suppliers in each manufacturing process. The numerical example verified the ability of the proposed approach regarding the selection and the allocation of suppliers. Therefore, the two-stage game theory approach helps the Supply Chain Management (SCM) managers with their supplier evaluation, selection, and order assignment.

Future work can be done with actual data to verify the proposed framework. Moreover, this research can be extended to examine supplier selection problem considering environment [50,51,60], and Big Data [61].

\section{Acknowledgments}

The author would like to thank the editor, the anonymous referees for their helpful suggestions, and the Ministry of Science and Technology, Taiwan, R.O.C. for financing this research project MOST 108-2410-H147-003.

\section{References}

1. Keyvanloo, M., Kimiagari, A.M., and Esfahanipour, A. "Risk analysis of sourcing problem using stochastic programming", Scientia Iranica, Transaction E: Industrial Engineering, 21(3), pp. 1034-1043 (2014).

2. Choi, T.Y. and Hartley, J.L. "An exploration of supplier selection practices across the supply chain", Journal of Operations Management, 14(4), pp. 333343 (1996)

3. Rao, C.J., Zheng, J.J., Hu, Z., and Goh, M. "Compound mechanism design in multi-attribute and multisource procurement of electricity coal", Scientia Iranica, Transactions E: Industrial Engineering, 23(3), pp. 1384-1398 (2016).

4. Dickson, G.W. "An analysis of vendor selection systems and decisions", Journal of Purchasing, 2(1), pp. 5-17 (1966).

5. Weber, C.A., Current, J.R., and Benton, W.C. "Vendor selection criteria and methods", European Journal of Operational Research, 50(1), pp. 2-18 (1991).

6. Weber, M., Hiete, M., Lauer, L., and Rentz, O. "Low cost country sourcing and its effects on the total cost of ownership structure for a medical devices manufacturer", Journal of Purchasing and Supply Management, 16(1), pp. 4-16 (2010).

7. Maurizio, B. and Alberto, P. "From traditional purchasing to supplier management: A fuzzy logic-based approach to supplier selection", International Journal of Logistics, 5(3), pp. 235-255 (2002).
8. Chan, T.S.F. and Kumar, N. "Global supplier development considering risk factors using fuzzy extended AHP-based approach", Omega, 35(4), pp. 417-431 (2007).

9. Freeman, J. and Chen, T. "Green supplier selection using an AHP-Entropy-TOPSIS framework", Supply Chain Management: An International Journal, 20(2), pp. 327-340 (2015).

10. Neyestani, M.S., Jolai, F., and Golmakani, H.R. "An evolutionary algorithm for supplier order allocation with fuzzy parameters considering linear and volume discount", Scientia Iranica, Transaction E: Industrial Engineering, 22(3), pp. 1130-1141 (2015).

11. Hosseini, S. and Barker, K. "A Bayesian network model for resilience-based supplier selection", International Journal of Production Economics, 180, pp. 68-87 (2016).

12. Tezenji, F.R., Mohammadi, M., Pasandideh, S.H.R., and Koupaei, M.N. "An integrated model for supplier location-selection and order allocation under capacity constraints in an uncertain environment", Scientia Iranica, Transactions E: Industrial Engineering, 23(6), pp. 3009-3025 (2016).

13. Wetzstein, A., Hartmann, E., Benton Jr., W.C., and Hohenstein, N.O. "A systematic assessment of supplier selection literature - State-of-the-art and future scope", International Journal of Production Economics, 182, pp. 304-323 (2016).

14. Zaheri, F., Zandieh, M., and Taghavifard, M.T. "Bilevel programming for supplier selection under quantity discount policy", Scientia Iranica, Transactions E: Industrial Engineering, 24(4), pp. 2095-2104 (2017).

15. Adeinat, H. and Ventura, J.A. "Integrated pricing and supplier selection in a two-stage supply chain", International Journal of Production Economics, 201, pp. 193-202 (2018).

16. Rabieh, M., Modarres, M., and Azar, A. "Robustfuzzy model for supplier selection under uncertainty: An application to the automobile industry", Scientia Iranica, Transactions E: Industrial Engineering, 25(4), pp. 2297-2311 (2018).

17. Mohammaditabar, D., Ghodsypour, S.H., and Hafezalkotob, A. "A game theoretic analysis in capacityconstrained supplier-selection and cooperation by considering the total supply chain inventory costs", International Journal of Production Economics, 181, pp. 87-97 (2016).

18. Liu, T., Deng, Y., and Chan, F. "Evidential supplier selection based on DEMATEL and game theory", International Journal of Fuzzy System, 20(4), pp. 1321-1333 (2018).

19. Von Neumann, J. and Morgenstern, O., Theory of Games and Economic Behavior, Princeton University Press, Princeton, New Jersey (1944).

20. Nash, J. "Non-cooperative games", Annals of Mathematics, 54(2), pp. 286-295 (1951). 
21. LaValle, S.M., Planning Algorithms, Cambridge University Press, Cambridge, New York (2006).

22. Shapley, L.S. "A value for $n$-person games", In Contributions to the Theory of Games Vol. II H.W. Kuhn and A.W. Tucker, Princeton University Press, Princeton, New Jersey (1953).

23. Roth, A.E., The Shapley Value: Essays in Honor of Lloyd S. Shapley, Cambridge University Press, Cambridge, New York (1988).

24. Samuelson, L. "Game theory in economics and beyond", Journal of Economic Perspectives, 30(4), pp. 107-130 (2016).

25. Fudenberg, D. and Levine, D.K. "Whither game theory? Towards a theory of learning in games", Journal of Economic Perspectives, 30(4), pp. 151-170 (2016).

26. Dixit, A.K., Skeath, S., and Reiley Jr., D.H., Games of Strategy, 4th Ed., W. W. Norton \& Company, New York (2015).

27. Huang, Z. and Li, S.X. "Co-op advertising model in manufacturer-retailer supply chains: A game theory approach", European Journal of Operation Research, 135(3), pp. 527-544 (2001).

28. Leng, M. and Parlar, M. "Game theoretic applications in supply chain management: A review", INFOR, 43(3), pp. 187-220 (2005).

29. Peldschus, F. and Zavadskas, E.K. "Fuzzy matrix games multi-criteria model for decision-making in engineering", Informatica, 16(1), pp. 107-120 (2005).

30. Hennet, J.C. and Arda, Y. "Supply chain coordination: A game-theory approach", Engineering Applications of Artificial Intelligence, 21(3), pp. 399-405 (2008).

31. Bompard, E., Carpaneto, E., Ciwei, G., et al. "A game theory simulator for assessing the performances of competitive electricity markets", Electric Power Systems Research, 78(2), pp. 217-227 (2008).

32. Long, R. and Yu, L. "Study on regulation design about energy-saving and emission-reduction based on game theory", Procedia Earth and Planetary Science, 1(1), pp. 1641-1646 (2009).

33. Chen, Y.M., Wu, D., and Wu, C.K. "A game theory approach for evaluating terrorist threats and deploying response agents in urban environments", Journal of Homeland Security and Emergency Management, 6(1), Article 31, pp. 1-25 (2009).

34. Runyan, P., Heping, W., Zhengping, W., and Yu, L. "Decision-making of aircraft optimum configuration utilizing multi-dimensional game theory", Chinese Journal of Aeronautics, 23(2), pp. 194-197 (2010).

35. Madani, K. "Game theory and water resources", Journal of Hydrology, 381(3-4), pp. 225-238 (2010).

36. Charilas, D.E. and Panagopoulos, A.D. "A survey on game theory applications in wireless networks", Computer Networks, 54(18), pp. 3421-3430 (2010).

37. Sharma, R. and Gopal, M. "Synergizing reinforcement learning and game theory - A new direction for control", Applied Soft Computing, 10(3), pp. 675-688 (2010).
38. Dayi, H. and Jianwei, G. "Carbon abatement game between regulator and firms", Energy Procedia, 5, pp. 1859-1863 (2011).

39. Liu, W.Y., Yue, K., Wu, T.Y., and Wei, M.J. "An approach for multi-objective categorization based on the game theory and Markov process", Applied Soft Computing, 11(6), pp. 4087-4096 (2011).

40. Tiwari, S., Cárdenas-Barrón, L.E., Goh, M., and Shaikh, A.A. "Joint pricing and inventory model for deteriorating items with expiration dates and partial backlogging under two-level partial trade credits in supply chain", International Journal of Production Economics, 200, pp. 16-36 (2018).

41. Tiwari, S., Cárdenas-Barrón, L.E., Khanna, A., and Jaggi, C.K. "Impact of trade credit and inflation on retailer's ordering policies for non-instantaneous deteriorating items in a two-warehouse environment", International Journal of Production Economics, 176, pp. $154-169$ (2016).

42. Tiwari, S., Jaggi, C.K., Bhunia, A.K., et al. "Twowarehouse inventory model for non-instantaneous deteriorating items with stock-dependent demand and inflation using particle swarm optimization", Annals of Operations Research, 254(1-2), pp. 401-423 (2017).

43. Tiwari, S., Jaggi, C.K., Gupta, M., and CárdenasBarrón, L.E. "Optimal pricing and lot-sizing policy for supply chain system with deteriorating items under limited storage capacity", International Journal of Production Economics, 200, pp. 278-290 (2018).

44. Tiwari, S., Wee, H.M., and Sarkar, S. "Lot-sizing policies for defective and deteriorating items with time-dependent demand and trade credit", European Journal of Industrial Engineering, 11(5), pp. 683-703 (2017).

45. Jaggi, C.K., Tiwari, S., and Goel, S.K. "Credit financing in economic ordering policies for non-instantaneous deteriorating items with price dependent demand and two storage facilities", Annals of Operations Research, 248(1-2), pp. 253-280 (2017).

46. Gimenez, C. and Tachizawa, E. "Extending sustainability to suppliers: a systematic literature review", Supply Chain Management, 17(5), pp. 531-543 (2012).

47. Tiwari, S., Daryanto, Y., and Wee, H.M. "Sustainable inventory management with deteriorating and imperfect quality items considering carbon emission", Journal of Cleaner Production, 192, pp. 281-292 (2018).

48. Rabieh, M., Rafsanjani, A.F., Babaei, L., and Esmaeili, M. "Sustainable supplier selection and order allocation: An integrated Delphi method, fuzzy topsis, and multi-objective programming model", Scientia Iranica, Transactions E: Industrial Engineering, 26(4), pp. 2524-2540 (2019).

49. Fiestras-Janeiro, M.G., Garcia J.I., Meca, A., and Mosquera, M.A. "Cooperative game theory and inventory management", European Journal of Operational Research, 210(3), pp. 459-466 (2011). 
50. Zhao, R., Neighbour, G., Han, J., et al. "Using game theory to describe strategy selection for environmental risk and carbon emissions reduction in the green supply chain", Journal of Loss Prevention in the Process Industries, 25(6), pp. 927-936 (2012).

51. Zhao, R., Neighbour, G., McGuire, M., and Deutz, P. "A software based simulation for cleaner production: A game between manufacturers and government", Journal of Loss Prevention in the Process Industries, 26(1), pp. 59-67 (2013).

52. Wu, P.I., Chen, C.T., Cheng, P.C., and Liou, J.L. "Climate game analyses for CO2 emission trading among various world organization", Economic Modelling, 36, pp. 441-446 (2014).

53. Sadigh, A.N., Chaharsooghi, S.K., and Sheikhmohammady, M. "Game-theoretic analysis of coordinating pricing and marketing decisions in a multi-product multi-echelon supply chain", Scientia Iranica, Transactions E: Industrial Engineering, 23(3), pp. 14591473 (2016).

54. Nazari, L., Seifbarghy, M., and Setak, M. "Modeling and analyzing pricing and inventory problem in a closed-loop supply chain with return policy and multiple manufacturers and multiple sales channels using game theory", Scientia Iranica, Transaction E: Industrial Engineering, 25(5), pp. 2759-2774 (2018).

55. Wu, C.K. "A game theory approach for assessing risk value and deploying search-and-rescue resources after devastating tsunamis", Environmental Research, 162, pp. 18-26 (2018).

56. Cheheltani, S.H. and Ebadzadeh, M.M. "Immune based approach to find mixed Nash equilibrium in normal form games", Journal of Applied Sciences, 10(6), pp. 487-193 (2010).

57. Wu, C.K., DRAG: Deploying Response Resources for MAS Agents Using Game Theory, Amazon Digital Service LLC, Kindle Edition (2015).

58. El-Shazly, A. "Strategic interaction between governments and investors under privatization programs", Managerial and Decision Economics, 33(1), pp. 29-38 (2012).

59. Alpcan, T. and Başar, T. "Network security: A decision and game-theoretic approach", Cambridge University Press, Cambridge, New York (2010).

60. Kumar, A., Jain, V., and Kumar, S. "A comprehensive environment friendly approach for supplier selection", Omega, 41(1), pp. 109-123 (2014).
61. Lamba, K., Singh, S.P., and Mishra, N. "Integrated decisions for supplier selection and lot-sizing considering different carbon emission regulations in big data environment", Computers \& Industrial Engineering, 128, pp. 1052-1062 (2019).

\section{Biographies}

Jonas C.P. Yu received his $\mathrm{PhD}$ in Industrial Management at National Central University (Taiwan) in 2006 and his MSc degree from Chung Yuan Christian University (Taiwan) in 1995. After a long career in several international firms, he is now an Associate Professor of Logistics Management at Takming University of Science and Technology and an Adjunct Professor at Chung Yuan Christian University. His research interests are production \& material control, inventory and supply chain management, optimization problems, and yield management.

Hui-Ming Wee is a Distinguished Professor of Industrial \& Systems Engineering at the Chung Yuan Christian University (Taiwan). He received his BSc (Hons) in Electrical and Electronic Engineering from the Strathclyde University (UK), MEng in Industrial Engineering and Management from the Asian Institute of Technology (AIT), and PhD in Industrial Engineering from the Cleveland State University, Ohio (USA). His research interests lie in the field of production/inventory control, optimization, and supply chain management.

Schnell Jeng is a PhD Candidate in Industrial \& Systems Engineering at the Chung Yuan Christian University (Taiwan).

Yosef Daryanto is currently working at the Department of Industrial Engineering, Universitas Atma Jaya Yogyakarta in Indonesia. He received his BCs degree in Industrial Engineering from Universitas Atma Jaya Yogyakarta (Indonesia), MSc degree in International Technology Transfer Management from the Technische Fachhochschule Berlin (Germany), and PhD degree in Industrial and Systems Engineering from the Chung Yuan Christian University (Taiwan). His current research interests include inventory control, supply chain management, and sustainability. 